\title{
Fluorinated chemicals need stricter control
}

$\mathrm{S}$ cientists at Environment Canada went public in a rare interview to confirm that they largely agree with a statement signed by more than 200 scientists worldwide that warns about health risks from a family of 150 or more fluorinated chemicals known as perfluoroalkyl and polyfluoroalkyl substances (PFASs), which are widely used as stain and water repellents. PFASs came to international attention as environmental and human health hazards in large part because of the work of Canadian scientists that began over a decade ago.

The Madrid Statement on Poly- and Perfluoroalkyl Substances (PFASs), published in Environmental Health Perspectives, was authored by eight scientists including Miriam Diamond, a professor in earth sciences at the University of Toronto. It indicates that PFASs are highly persistent in the environment as well as human and animal tissue, and "degrade very slowly, if at all. ..." Diamond describes the statement as an "important initiative" in spurring international control efforts.

The statement calls for greater scientific scrutiny, and tougher national and international controls alongside industry phase-outs and consumer transparency. It urges people to avoid products containing, or manufactured using PFASs, which are embedded in everything from raincoats to patio furniture, hair straighteners to cellphones.

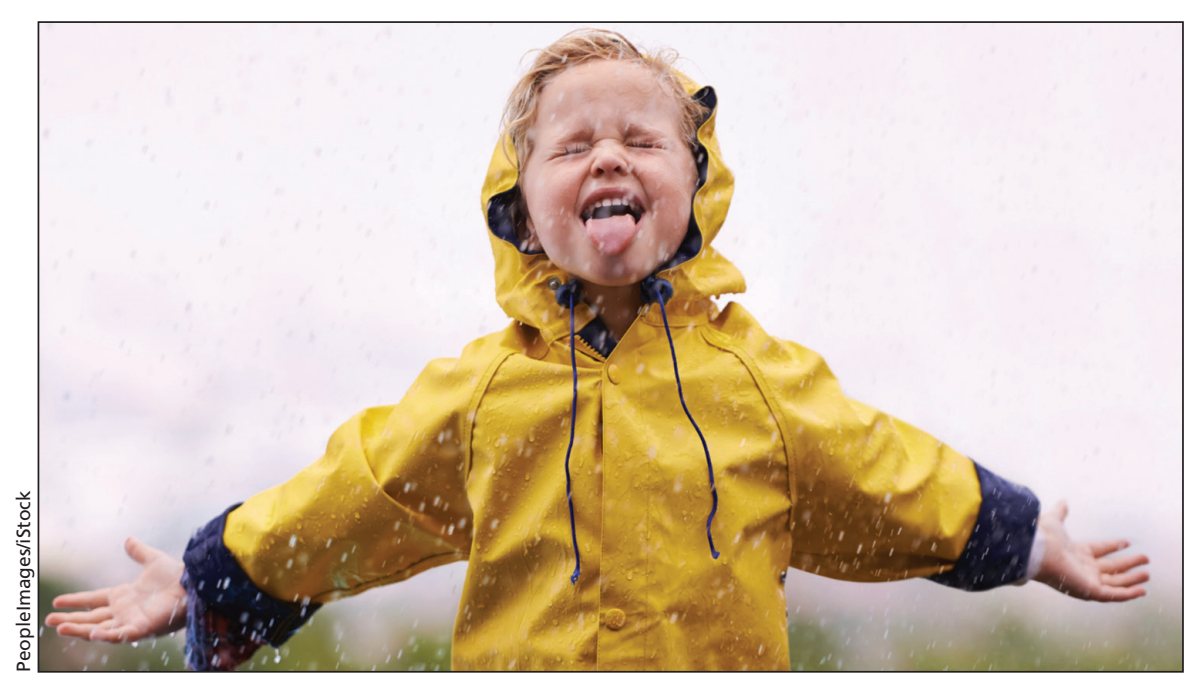

Perfluoroalkyls, which are widely used as stain and water repellants, negatively affect both the environment and human health.

In human studies, the statement notes, PFASs are linked to testicular and kidney cancers, liver malfunction, hypothyroidism, high cholesterol, ulcerative colitis, lower birth weight and size, obesity, decreased immune response to vaccines, and reduced hormone levels and delayed puberty.

Robert Chénier, director of the Ecological Assessment Division at Environment Canada, cited pioneering Canadian government-supported studies that first helped raise awareness about the chemicals. He concludes that "Some of the PFAS compounds are very bad for the environment, and some are obviously not as bad."

A rebuttal to the Madrid statement in the May issue of Environmental Health Perspectives by the American Chemistry Council says it "ignores a large body of scientific information demonstrating important differences between the health and environmental impacts of long-chain and short-chain PFASs. The US Environmental Protection Agency and other regulators have approved numerous shortchain alternatives to replace long-chain PFASs."The council also notes that some shorter-chain compounds are less toxic and have substantially shorter half-lives than some longer-chain compounds.

University of Alberta environmental chemist Jonathan Martin was among the first scientists to identify perfluorooctane sulfonate (PFOS) - a type of PFAS used in non-stick cookware - as a haz- ard and is one of six Canadians who signed the Madrid statement. He says the chemical industry previously responded to the ban on some PFASs by "rushing to fill the void with chemicals that do the same thing." This leaves scientists and regulators playing catch-up, often with very limited information about these alternative compounds.

Chénier says "Canada is actually ahead of most other countries" in confronting the PFAS hydra. Nevertheless, millions of products that may contain PFASs still come into Canada daily. "And you really cannot verify what every item contains," says Chénier.

Managing risk largely depends on managing the disposal of PFAS-containing products, says Christopher S. Marshall, Environment Canada's director of risk management for persistent organic pollutants. Typically, these products end up in landfill sites with consequent environmental exposure. "We are working with the provinces and territories to achieve better waste management," Marshall said, citing efforts by the Canadian Council of Ministers of the Environment (CCME) to shift "the expenses associated with product end-of-life management from taxpayers to producers and consumers" and reduce "the amount of waste generated and going to disposal."

According to a 2009 CCME report, Canada's waste management performance lags behind other G8 and Organisation for Economic Co-operation and Development countries.

The consequences of loose control of PFASs are outlined in various Health Canada studies, Chénier notes. Health Canada acknowledges in a 2007 report that "Nearly all Canadians carry low levels of perfluorinated chemicals, including PFOS, in their blood as a result of exposure."

Chénier and Marshall agree that PFAS control hinges on integrating ongoing scientific investigation with domestic and international regulations, alongside industry phase-outs, and consumer awareness - all of which are also emphasized in the Madrid statement. Paul Christopher Webster, Toronto, Ont.

CMAJ 2015. DOI:10.1503/cmaj.109-5083 